\title{
Competitividad del sector del transporte terrestre intermunicipal de pasajeros en Boyacá, Colombia: una aproximación al estado del arte
}

\author{
Diego Armando Rodríguez-Álvarez ${ }^{*}$ Rosa Nely Pérez-Martínez
}

* Candidato a Magíster en Administración de Organizaciones. Investigador del Centro Regional de Gestión para la Productividad de Boyacá (CRePIB), Universidad Pedagógica y Tecnológica de Colombia, Tunja, Colombia. Correo electrónico:

diego.rodriguez@crepib.org.co

* Magíster en Administración. Profesor e investigador del Centro Regional de Gestión para la Productividad de Boyacá (CREPIB), Escuela de Administración de Empresas, Universidad Pedagógica y Tecnológica de Colombia, Tunja, Colombia.

Correo electrónico:

rosa.perez@uptc.edu.co

Recibido: 30 de noviembre del 2015

Aceptado: 31 de mayo del 2016

Cómo citar este artículo: RodríguezÁlvarez, D. A. y Pérez-Martínez, R. N. (2016). Competitividad del sector de transporte terrestre intermunicipal de pasajeros en Boyacá: una aproximación al estado del arte. Cooperativismo \& Desarrollo, 24(109), xx-xx. doi: 10.16925/co.v24i109.1511

\section{Resumen}

Introducción: la competitividad se ha convertido en un elemento que caracteriza la dinámica de un sector o una organización, y su búsqueda ha llevado a la construcción y aplicación de herramientas que permiten mejorar las condiciones en las que las organizaciones compiten en el mercado. Metodología: nuestro desarrollo metodológico se basó en la consulta y el análisis de fuentes documentales que permitieran establecer el estado en el cual se halla la investigación sobre el sector involucrado. Dicha revisión permite mostrar que no ha existido, por tradición, un interés investigativo en el sector, salvo en sus aspectos puramente técnicos (sobre los que han sido realizadas investigaciones por instituciones educativas de nivel superior), mas no en el campo de su gestión. Resultados: esta investigación presenta resultados de una revisión teórica sobre la competitividad del transporte intermunicipal de pasajeros por carretera en Boyacá (Colombia) con el ánimo de colaborar a investigaciones más profundas que contribuyan al desarrollo de este sector en la región. Conclusiones: se concluye que es necesario profundizar en investigaciones sobre los elementos que propician la competitividad del sector.

Palabras clave: calidad, competitividad, tendencias en transporte, transporte intermunicipal de pasajeros. 


\title{
Competitiveness of the intercity land transport industry in Boyacá, Colombia: an approach to the state of the art
}

\begin{abstract}
Introduction: Competitiveness has become an element that characterizes the dynamics of a sector or organization, and its search has led to the construction and implementation of tools to improve the conditions in which organizations compete in the market. Methodology: Our methodological development was based on the consultation and analysis of documentary sources that allowed the state of research on the sector to be established. This review showed that traditionally there has not been a research interest in the sector, save in its purely technical aspects (on which research has been carried out by institutions of higher education). The field of its management, however, has not been studied. Results: This research presents the results of a theoretical review of the competitiveness of intercity land transport in Boyacá (Colombia), with the aim of encouraging further research to contribute to the development of this sector in the region. Conclusions: It was concluded that further research is needed on the elements that promote the competitiveness of the sector.
\end{abstract}

Keywords: quality, competitiveness, transportation trends, intercity land transport.

\section{Competitividade do setor do transporte terrestre intermunicipal de passageiros em Boyacá, Colômbia: uma aproximação ao estado da arte}

\section{Resumo}

Introdução: a competitividade transformou-se num elemento que caracteriza a dinâmica de um setor ou de uma organização, e sua busca levou à construção e à aplicação de ferramentas que permitem melhorar as condições nas quais as organizações competem no mercado. Metodologia: nosso desenvolvimento metodológico baseou-se na consulta e na análise de fontes documentárias que permitissem estabelecer o estado no qual se encontra a pesquisa sobre o setor envolvido. Essa revisão permite mostrar que não existiu, por tradição, um interesse investigativo no setor, salvo em seus aspectos puramente técnicos (sobre as pesquisas que foram realizadas por instituições educativas de nível superior), mas não no campo de sua gestão. Resultados: esta pesquisa apresenta resultados de uma revisão teórica sobre a competitividade do transporte intermunicipal de passageiros por estrada em Boyacá (Colômbia) com o objetivo de colaborar para promover pesquisas mais profundas que contribuam para o desenvolvimento desse setor na região. Conclusões: conclui-se que é necessário aprofundar em pesquisas sobre os elementos que propiciam a competitividade do setor.

Palavras-chave: qualidade, competitividade, tendências em transporte, transporte intermunicipal de passageiros. 


\section{Introducción ${ }^{1}$}

Actualmente, la competitividad es un tema de interés general para la comunidad académica, empresarial y estatal. Se considera que, en el marco de la globalización, el nuevo reto de las organizaciones es propiciar condiciones favorables que les permitan, mediante la creación de valor, sostenerse en el mercado, especialmente cuando las condiciones del entorno son cada vez más exigentes. Esta situación se refleja principalmente en el acelerado ritmo en el campo de la tecnología, en el que el creciente grado de innovación impone nuevas tendencias. Por ende, las organizaciones deben recurrir a la innovación en sus diferentes dimensiones para crear y mantener ventajas competitivas fundadas en la diferenciación de los elementos de la cadena de valor y el aprovechamiento de sus ventajas comparativas (dadas por las condiciones naturales y geográficas del entorno).

Como resultado del proyecto Análisis de las brechas competitivas del sector transporte intermunicipal de pasajeros en Boyacá ${ }^{2}$, se evidenció un vacío en cuanto a la disponibilidad de información para determinar la situación económica y competitiva del sector. Este vacío intenta ser llenado con la presente investigación, que ofrece en una aproximación al estado del arte de la competitividad en el sector del transporte intermunicipal de pasajeros en Boyacá. La investigación ha sido elaborada con el propósito de contribuir a la construcción de conocimiento, y para originar nuevas preguntas, nuevas problemáticas y nuevas áreas de investigación (Páramo, 2013). En otras palabras, se pretende responder los siguientes interrogantes acerca del tema de la competitividad del transporte intermunicipal en la región: ¿Qué se ha dicho? ¿Cómo se ha dicho? ¿Qué logros se han alcanzado? ¿Qué no se ha dicho? ¿Qué vacíos existen?

El presente artículo consta de cuatro partes. La primera contiene las generalidades de la competitividad y las diferentes teorías relacionadas con los modelos de análisis competitivo y de la competitividad de los servicios. La segunda parte se refiere al estado actual de la competitividad en Colombia y Boyacá,

1 Artículo de investigación científica, resultado del proyecto titulado "Análisis de las brechas competitivas del sector transporte intermunicipal de pasajeros en el departamento de Boyacá".

2 Ejecutado por el Centro Regional de Gestión para la Productividad de Boyacá CREPIB y la Universidad Pedagógica y Tecnológica de Colombia UPTC, Tunja, en el 2013. como referente de análisis, en el entorno del sector del transporte intermunicipal de pasajeros. La tercera parte resume las tendencias competitivas a nivel mundial, nacional y departamental con relación al transporte de pasajeros. Finalmente, en la cuarta parte, se presentan las conclusiones y referencias utilizadas.

\section{¿Qué es la competitividad?}

En los últimos años, el término competitividad se ha utilizado con mucha frecuencia en diferentes contextos, como en el ámbito territorial y organizacional, con el propósito de establecer qué tan sostenibles pueden ser las organizaciones en el entorno de acuerdo con la capacidad para generar valor agregado (estrechamente relacionado con el potencial de los sectores productivos). En este sentido, son importantes factores como el grado de desarrollo del sistema objeto de análisis, así como los determinantes y la variación de actores estratégicos que diferencian a las regiones, las empresas y los países.

La Real Academia de la Lengua Española (RAE, 2001) define competitividad como la capacidad de competir y como la rivalidad para la consecución de un fin. Una definición muy concreta que enmarca la esencia de la competitividad, la cual no es más que la capacidad que tienen las organizaciones para sostenerse en el mercado.

Uno de los autores más citados en cuanto al tema de la competitividad es Michael Porter, quien, en su libro La ventaja competitiva de las naciones, dice sobre la competitividad que:

La prosperidad de una nación depende de su competitividad, la cual se basa en la productividad con la cual esta produce bienes y servicios. Políticas macroeconómicas e instituciones legales sólidas y políticas estables, son condiciones necesarias pero no suficientes para asegurar una economía próspera. La competitividad está fundamentada en las bases microeconómicas de una nación: la sofisticación de las operaciones y estrategias de una compañía y la calidad del ambiente microeconómico de los negocios en el cual las compañías compiten. Entender los fundamentos microeconómicos de la competitividad es vital para la política económica nacional (Porter, 2008, p. 18). <Fin de cita $>$

Desde un enfoque empresarial, Porter (1985) define la competitividad como la capacidad de una 
empresa para producir y mercadear productos en mejores condiciones de precio, calidad y oportunidad que sus rivales.

En otra visión, se dice que la competitividad es un concepto que no tiene límites precisos y se define en relación con otros conceptos. La definición operativa de competitividad depende del punto de referencia del análisis (nación, sector, firma), del tipo de producto analizado (bienes básicos, productos diferenciados, cadenas productivas, etapas de producción) y del objetivo de la indagación (corto o largo plazo, explotación de mercados, reconversión, etcétera; Piñeiro et al., 1993). Esta definición permite identificar ampliamente el nivel de estudio, el cual dependerá, en gran medida, de parámetros y variables ligados al punto de referencia del análisis.

Por otra parte, la Comisión Económica para América Latina y el Caribe (CEPAL) considera que la competitividad auténtica se fundamenta en la incorporación de tecnología y el uso renovable de los recursos naturales. Esta concepción contrasta con el concepto tradicional de competitividad basado, precisamente, en el aprovechamiento de los recursos humanos y naturales (citado en Velasco y Heredia, 2004).

La organización World Economic Forum (WEF) define competitividad como el conjunto de instituciones, políticas y factores que determinan el nivel de productividad de un país. El nivel de productividad, a su vez, determina el nivel de prosperidad que puede alcanzar una economía. El nivel de productividad determina, también, las tasas de rendimiento obtenido por las inversiones y define las tasas de crecimiento de una economía. Igualmente, la WEF define los doce pilares de la competitividad en su Global Competitiveness Index; entre ellos se encuentran: instituciones, infraestructura, macroeconomía, salud y educación primaria, alta educación y capacitación, eficiencia en el mercado de trabajo, sofisticación en el mercado financiero, disponibilidad de tecnologías, tamaño del mercado, sofisticación de los negocios e innovación (World Economic Forum, 2015). Los pilares de competitividad propuestos por la WEF se clasifican de acuerdo con la estructura mostrada en la figura 1.

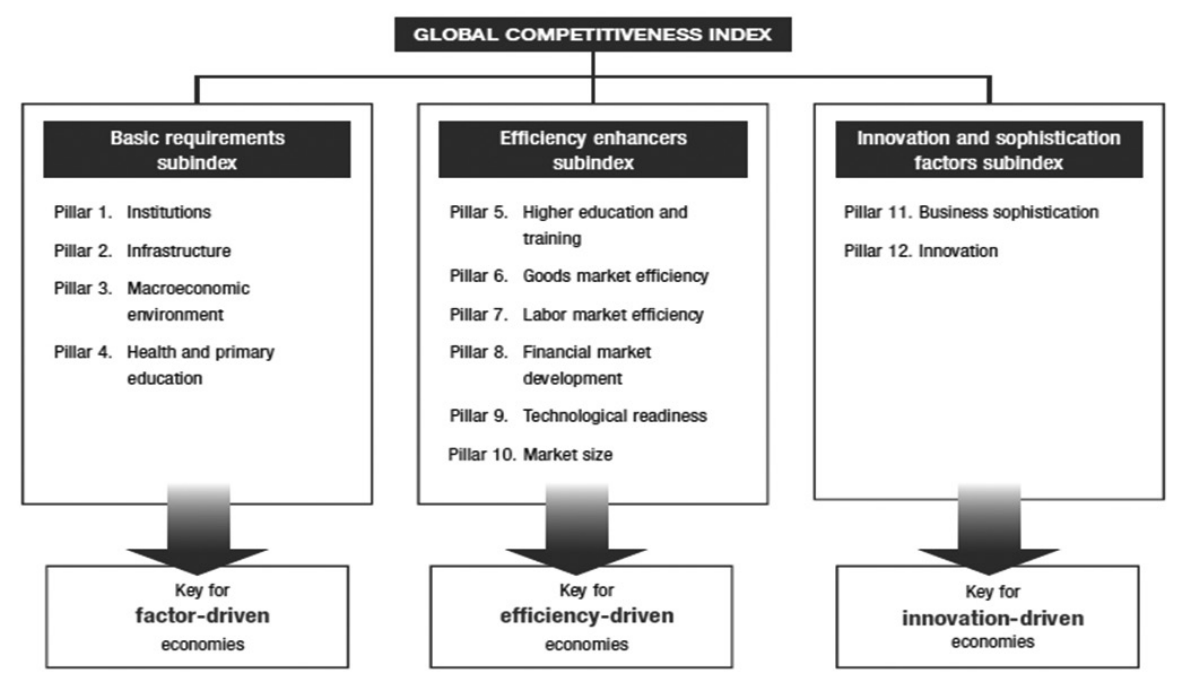

Figura 1. Índice global de competitividad weF. Tomada de World Economic Forum (2015).

\section{Modelos de competitividad}

A continuación se presentan algunos modelos de competitividad, quizá los más reconocidos en el ámbito académico y empresarial.

\section{Diamante de la Competitividad}

Consideremos el análisis teórico de la competitividad, a la que Porter (1985) define como la capacidad de una empresa para producir y mercadear productos en mejores condiciones de precio, calidad y oportunidad que sus rivales. Estos elementos que pueden inferir en el Diamante de la Competitividad (ver figura 2). En este se determina el potencial

3 Organización internacional para la cooperación público-Privada que reúne factores políticos, empresariales y de liderazgo de la sociedad para dar forma a las agendas globales, regionales e industriales de competitividad. 
competitivo de las organizaciones al establecer la relación de las condiciones de los factores de producción, la demanda, estrategia, estructura y rivalidad empresarial, así como dos elementos exógenos (Gobierno y azar).

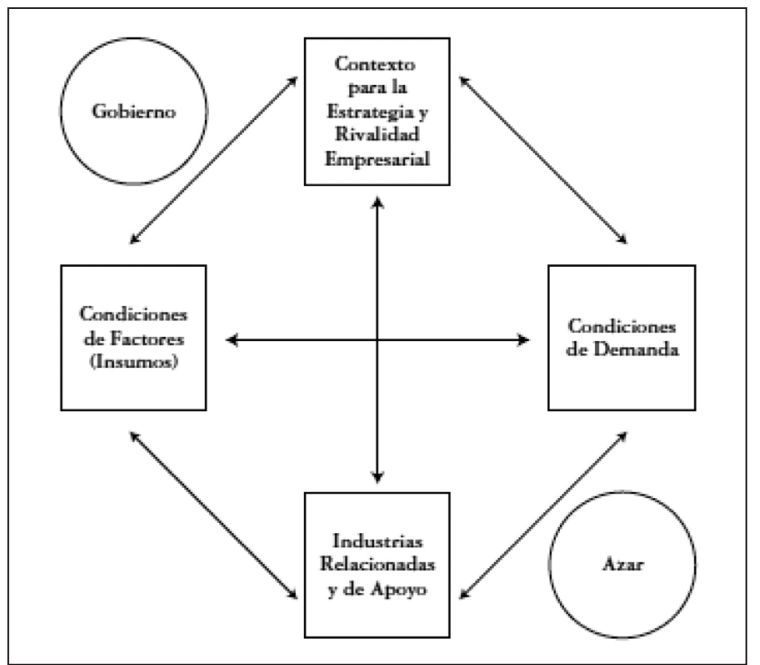

Figura 2. Diamante de la Competitividad. Tomada de Lombana y Rozas-Gutiérrez (2008).

El análisis de los componentes del Diamante de la Competitividad de Porter, representados en la figura 2 , se presenta a continuación:

\section{Las condiciones de los factores}

En este factor se tiene en cuenta el concepto de ventaja comparativa (justificado por los criterios de producción clásicos, capital, tierra o trabajo que poseen las empresas). Además de los anteriores elementos, incorpora un elemento clave relacionado con la tecnología, la cual representa una ventaja competitiva que permite que los demás factores puedan desarrollarse.

\section{Condiciones de la Demanda}

Se refieren a la sofisticación de la demanda interna doméstica con la que las empresas pueden garantizar la máxima calidad o eficiencia de sus productos o servicios.

\section{Contexto para la estrategia y la rivalidad empresarial}

En este factor se considera el ambiente competitivo microeconómico propiamente dicho. En otras palabras, el nivel de la competencia local que determina las condiciones del mercado.

\section{Industrias relacionadas y de apoyo}

Se refiere a la cooperación con las diferentes empresas conexas de apoyo, las cuales, a su vez, compiten actuando como clúster, es decir, un grupo de empresas que trabajan en un mismo sector a fin de alcanzar unos objetivos en común. Como por ejemplo en el sector de tecnología, las empresas conforman clúster para la adquisición de materias primas) desde un enfoque intrasectorial, y como cadena de valor, desde una perspectiva intersectorial.

Por otra parte, Porter deja entrever que el Gobierno es una variable exógena, pues este no afecta a los demás determinantes, al mismo tiempo que no resulta afectado por las demás variables. Al igual que el Gobierno, el azar afecta los determinantes de la competitividad, dado que fenómenos o situaciones del entorno, como el cambio climático y las guerras, no pueden ser controlados (citado en Lombana y Rozas-Gutiérrez, 2008).

\section{Competitividad sistémica}

Un grupo de investigadores del Instituto Alemán del Desarrollo propone el modelo de la competitividad sistémica. Este surge como una herramienta teórica necesaria ante los niveles de complejidad alcanzados por la propia sociedad en la era de la globalización y el cambio tecnológico (Esser, Hillebrand, Messener y Stamer, 1994). El concepto de competitividad sistémica enfatiza los siguientes aspectos: la competitividad de la economía se fundamenta en medidas engranadas entre sí que apuntan a objetivos concretos teniendo en cuenta cuatro niveles del sistema (meta, macro, micro y meso, como se puede ver en la figura 3). Otro aspecto fundamental de la competitividad sistémica se refiere al concepto pluridimensional de conducción que se compone de competencia, diálogo y toma conjunta de decisiones, en el cual se incluye a los grupos importantes de actores (Esser et al., 1994). Asimismo, este modelo establece como premisa fundamental la integración social, que no solamente se sustenta en reformas económicas, sino también un proyecto de transformación de la sociedad (Hernández, 2006). 


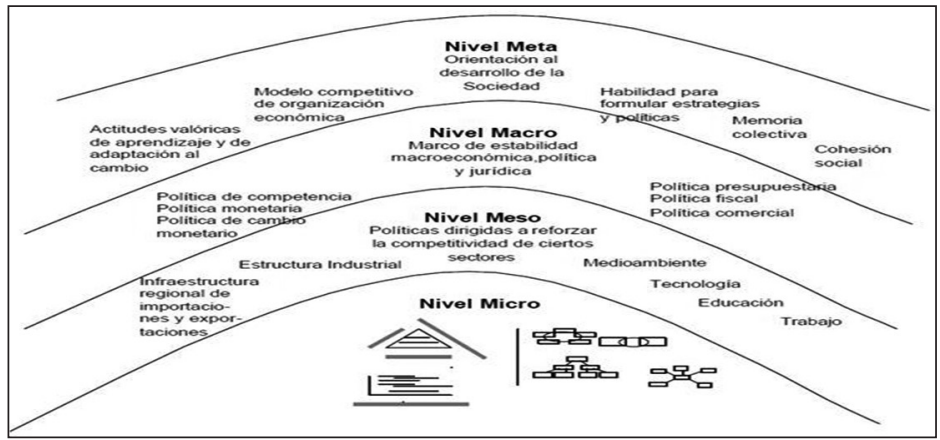

Figura 3. Competitividad Sistémica. Tomada de Esser et al. (1994).

El modelo de la competitividad sistémica da a entender de forma amplia y clara la integración de la competitividad en sus diferentes niveles de análisis, no solo desde la perspectiva empresarial, sino también en relación con el sector, la región, el país y las políticas que provee. En el ámbito de las empresas, la ventaja competitiva de los métodos de producción y organización facilita la competitividad en términos de precio y calidad de producto final. En una industria, se relaciona con los costos y el valor agregado de los productos. En consecuencia, el desarrollo de la competitividad se fundamenta en las actividades que pueda adelantar el Gobierno en cuanto a la cohesión social, es decir, las acciones de las empresas (entendidas bajo el referente conceptual de los análisis micro, meso, macro y su interacción) para cooperar y competir (Romo y Musik, 2005). La competitividad sistémica, según Morales y Castellanos (2007), representa un importante referente que involucra las siguientes dimensiones.

\section{Analítica}

Aborda, a su vez, la competitividad en cuatro niveles: meta, macro, meso y micro. El nivel meta revisa la capacidad de una sociedad para la integración y la estrategia. El macro, examina aspectos como las políticas monetaria, fiscal, cambiaria, comercial y antimonopolio, la protección al consumidor, la estabilidad legal, y el ambiente económico y político. El meso evalúa la calidad de vida, el nivel de educación del talento humano, el desarrollo de la ciencia y la tecnología, el aprovechamiento sostenible del medio ambiente y el crecimiento local. En el micro se analiza la forma en que las empresas reaccionan a los requerimientos del entorno por medio de combinaciones organizativas, sociales y técnicas que permitan la consecución de la calidad y la eficiencia.

\section{Política}

Concierne a los ámbitos de la estructura institucional de un país (municipal, regional, nacional y supranacional), y asigna responsabilidades a cada actor del mismo.

\section{Clásica o funcional}

Se refiere a la integración de departamentos y funciones administrativas que busquen responder de forma eficiente al entorno en las organizaciones y en las instituciones.

Por último, cabe anotar que en el modelo de competitividad sistémica influyen, además de factores económicos y políticos, aspectos como la educación, la ciencia, la estabilidad política y los sistemas de valor. De esta manera, se considera un modelo sistémico, dado que las empresas que son competitivas requieren un ambiente de soporte de entidades suministradoras de bienes y servicios orientados a la producción (Lombarca, 2007).

\section{Cinco fuerzas competitivas}

De igual forma, la mayor contribución de Porter (1985) ha sido sistematizar las cinco fuerzas competitivas de una industria que determinan el comportamiento y los resultados de una empresa. Estas fuerzas son:

- Los competidores directos, que compiten por una misma necesidad con un mismo producto o tecnología.

- Los productos o servicios sustitutos.

- El poder de negociación de los clientes.

- El poder de negociación de los proveedores.

- La amenaza de aparición de nuevos competidores. 
De acuerdo con esto, la rivalidad entre empresas locales estimula la innovación y la actualización de las capacidades y determina la distribución del valor económico creado. Asimismo, dentro de los factores de competitividad, se señalan la innovación, el capital humano y la infraestructura (Lombana y RozasGuitérrez, 2008).

En resumen, se puede considerar que la competitividad está en función de la eficiencia macroeconómica de sus empresas, las políticas gubernamentales para promover el crecimiento económico y el desempeño de sus principales ciudades para atraer nuevas inversiones que generen empleos y coadyuven al crecimiento económico local. En este sentido, y dada la complejidad y diversidad de enfoques existentes, se puede clasificar la competitividad, según los factores que la determinan, en tres tipos: empresarial, estructural y sistémica (Castellanos y Ramírez, 2013).

La competitividad empresarial se establece a partir de factores relacionados con los campos de acción de las organizaciones, la toma de decisiones y ejecución de estas (como la gestión, la innovación, la producción y el recurso humano). La competitividad en una empresa está asociada con aspectos como el de la rentabilidad, la productividad, los costos, el valor agregado, el porcentaje de participación en el mercado, el nivel de exportaciones, la innovación tecnológica, la calidad de los productos, entre otros. También se pueden encontrar indicadores como productividad de la mano de obra, productividad del capital, etcétera.

La competitividad estructural se refiere a la mejora continua en función de nuevas alianzas y a través de la interacción entre empresas, gobiernos, industrias y regiones innovadoras. Estas interacciones incorporan los determinantes políticos y económicos del desarrollo industrial de un país, Estado o región en los niveles macro, meso y micro (Castellanos y Ramírez, 2013).

\section{Competitividad en el sector de los servicios}

La calidad en las organizaciones representa una estrategia de ventaja competitiva. Esta se ha venido reforzando con los procesos de globalización que favorecen la libre competencia, los rápidos cambios de la tecnología y una comunidad de consumidores cada vez más informados y con mayores niveles de exigencia (Alcalde, 2009). En otras palabras, la competitividad de un servicio está ligada a la calidad, constituye una estrategia de diferenciación para competir mejor debido a que, muchas veces, las empresas atienden los mismos públicos con productos o servicios similares, pero con notorias diferencias en la calidad del servicio que prestan.

LaEuropean FoundationforQualityManagement (EFQM) define la calidad como las formas a través de las cuales las compañías satisfacen las necesidades y expectativas de sus clientes, su personal y las entidades implicadas financieramente (citado en Cabo, 2014). En otras palabras, la calidad se refiere a lograr cumplir con las expectativas de los stakeholders. Por su parte, la Oficina Europea de Estadística (Eurostat) define calidad como un concepto multifacético en el que las dimensiones que se consideran más importantes dependen de las perspectivas de los usuarios, las necesidades y prioridades que varían entre los distintos grupos de clientes.

Partiendo de las anteriores definiciones, en la literatura se fijan los siguientes parámetros para establecer las condiciones requeridas para la prestación de un servicio de calidad. Las características de la producción de un servicio pueden resumirse en:

- Inseparabilidad. La producción y el consumo del producto se dan simultáneamente.

- Heterogeneidad. El servicio varía entre cliente y cliente, de forma que resulta difícil prever lo que espera recibir cada cliente.

- Intangibilidad. Dificultad para medir o poner a prueba un servicio y asegurar su calidad antes de prestarlo efectivamente.

- No almacenabilidad. El producto no consumido no puede almacenarse.

- Presencialidad. El servicio no puede prestarse si el cliente no está presente.

Las anteriores características dan cuenta de la dificultad que rodea al concepto de la calidad en los servicios y justifican los múltiples estudios realizados en este campo. Además, hay otras características, propias de un servicio, importantes para enfocar su diseño y producción, que deben mencionarse para comprender mejor sus diferencias con el resto de productos. Las siguientes características citadas por González (2004) hacen referencia a una de las normas más importantes del transporte de viajeros en Europa, la Norma UNE 13816:

- El producto de los servicios tiene un alto contenido en "atención al cliente".

- El producto de los servicios es la percepción del 
cliente sobre la calidad del servicio.

- El producto de los servicios puede personalizarse más que un producto industrial.

- El factor humano es uno de los elementos principales del producto de un servicio.

- La satisfacción del trabajador transmite satisfacción al cliente.

- El producto de los servicios no se puede cambiar o reemplazar.

- La demanda es estacional, muy variable según las franjas horarias $y$, a veces, imprevisible.

En el sector de los servicios es muy importante la atención al cliente, incluso más que la infraestructura. No basta con tener equipos modernos que permitan ofrecer un servicio de calidad, si la atención al cliente es deficiente. Por tanto, es necesario conocer sus preferencias, gustos y necesidades. Son los clientes quienes evalúan permanentemente, antes, durante y luego de la prestación del servicio, y son ellos los que determinan la calidad en función de su percepción, más no de la percepción de la de la organización que lo presta. La calidad del servicio es un proceso, que va desde la planeación hasta la ejecución, que requiere tiempo y se relaciona directamente con la mejora continua, donde se miden los resultados y, finalmente, en la retroalimentación, evaluar y corregir si es necesario. La calidad del servicio implica el compromiso de toda la organización.

De otra parte, si bien los factores físicos son importantes, no lo son menos los factores de carácter psicológico dado que la función servicio desaparece una vez finalizada su prestación: luego de eso ya no se deja inspeccionar. En este sentido, aparecen aspectos relativos a la percepción del servicio, asociados a factores psicológicos en virtud de las sensaciones, como respuesta a estímulos que provocan en el pasajero la prestación del mismo (CETMo, 2008). Mejía (2008) ratifica lo subjetivo de la calidad mediante una frase común en mercadeo: "el producto convence pero el servicio enamora". Lo anterior explica claramente que la relación del cliente con el servicio debe conducir a generar fidelidad y lealtad. De ahí la importancia de que el servicio al cliente como factor de competitividad sea propiciado por la cultura organizacional al fomentar una relación amable que logre satisfacer los intereses del cliente.

\section{La competitividad en Colombia}

En 1991, con la creación del Ministerio de Comercio Exterior, se formula la Política Nacional de
Productividad y Competitividad, con el objetivo de contribuir a las políticas de diversificación de la oferta exportable. Sin embargo, el mercado colombiano exige la sofisticación de la oferta interna, teniendo en cuenta la producción competitiva en el contexto de la apertura económica.

Las cadenas productivas surgen al finalizar los años noventa. Allí se inicia el conocimiento acerca de las ventajas del trabajo en clúster. Asimismo, mediante el programa Colombia compite, diferentes proyectos son realizados, a nivel sectorial, para fortalecer la competitividad. Se consolida el Sistema Administrativo Nacional de Competitividad (sNC), para el seguimiento de las actividades y políticas sectoriales, y se crea el Consejo Privado de Competitividad (CPC) en el 2006, conformado por el sector empresarial y la academia (Lombana y RozasGutiérrez, 2008).

Teniendo en cuenta esto, es necesario tratar la importancia de la formación de clúster en el ámbito regional ya que, según Porter (1997), tiene el potencial de afectar de manera positiva la competitividad mediante mecanismos como el incremento de la productividad para reducir los costos de transacción y de capital, elevar la capacidad de innovación y procurar el crecimiento de la productividad y, por último, estimular la expansión del conglomerado (citado en Romo y Musik, 2005).

Algunos enfoques mencionados anteriormente se retoman en el documento CONPES 3439, emitido por el Departamento Nacional de Planeación, en el que se asegura que la competitividad es la capacidad que tiene una nación para la producción eficiente de bienes y servicios con óptimos niveles de aceptación en los mercados externos (Departamento Nacional de Planeación, 2006). Así mismo, Castellanos y Ramírez (2013) afirma que las empresas logran competitividad a través de la localización de los activos específicos que una región o espacio geográfico les pueda suministrar. Esto, a su vez, se denomina ambiente de negocios y está relacionado con condiciones del nivel departamental, de ciudad o clúster que facilitan o inhiben el proceso de creación de valor en las empresas (citado en Castellanos y Ramírez, 2013).

El Informe del CPC (Consejo Privado de Competitividad, 2007) indica algunos elementos importantes, entre los que se destacan: el crecimiento en ciencia y tecnología, en infraestructura y logística, en educación; la reducción y optimización de las tasas impositivas a las rentas corporativas; y, por último, la reducción de la informalidad para la mejora de la 
competitividad. De igual manera, existen herramientas como el Índice Global de Competitividad (IGC) del WEF, el cual se ha convertido en el principal referente en materia de competitividad, a nivel mundial, para medir la posición competitiva de un país. Según este reporte, Colombia pasó, entre el 2010 y el 2014, del puesto 68, entre 139 países, al puesto 66, entre 144 países. De allí se infiere que el país está cada vez más lejos de la meta de convertirse en el tercer país más competitivo de la región, meta establecida en el plan Colombia Visión 2032 (Consejo Privado de Competitividad, 2007). Por lo tanto, existen grandes retos; por ejemplo, mayor innovación, mejoras en materia logística, uso de TIC, capacitación del capital humano, trabajo en clúster, vínculos entre universidad y empresa (Consejo Privado de Competitividad, 2015). Los más recientes resultados de la competitividad colombiana, arrojados por el Informe de Competitividad de la WEF reflejan que el país ocupa el puesto número 61 entre 140 países, con los siguientes resultados de acuerdo a los doce pilares de la competitividad (Schwab, 2015).

Tabla 1.

Indice Global de Competitividad para Colombia

\begin{tabular}{lcc} 
& $\begin{array}{c}\text { Rank } \\
\text { (out of } \\
140)\end{array}$ & $\begin{array}{c}\text { Score } \\
(1-7)\end{array}$ \\
\hline GCI 2015-2016 & $\mathbf{6 1}$ & $\mathbf{4 . 3}$ \\
GCI 2014-2015 (out of 144) & 66 & 4.2 \\
GCI 2013-2014 (out of 148) & 69 & 4.2 \\
GCI 2012-2013 (out of 144) & 69 & 4.2 \\
\hline Basic requirements (40.0\%) & 77 & $\mathbf{4 . 5}$ \\
1st pillar: institutions & 114 & 3.3 \\
2nd pillar: infrastructure & 84 & 3.7 \\
3rd pillar: Macroeconomic environment & 32 & 5.5 \\
4th pillar: Health and primary education & 97 & 5.3 \\
\hline Efficiency enhancers (50\%) & 54 & 4.3 \\
5th pillar: Higher education and training & 70 & 4.3 \\
6th pillar: Goods market efficiency & 108 & 4.0 \\
7th pillar: Labor market efficiency & 86 & 4.1 \\
8th pillar: Financial market development & 25 & 4.6 \\
9th pillar: Technological readness & 70 & 3.8 \\
10th pillar: Market size & 36 & 4.8 \\
\hline Innovation and sophistication factors (10.0\%) & $\mathbf{6 1}$ & $\mathbf{3 . 7}$ \\
11th pillar: Business sophistication & 59 & 4.1 \\
12th pillar: Innovation & 76 & 3.2 \\
\hline
\end{tabular}

Nota. Tomada de The Global Competitiveness Report 2015-2016, por K. Schwab, 2015.

\section{Competitividad en Boyacá}

Según el estudio "Índice de Competitividad Departamental"4, realizado en el 2015 por el CPC y la Universidad del Rosario, a través del Centro de Pensamiento en Estrategias Competitivas (CEPEC), Boyacá se ubica en la posición número 9 , entre 25 departamentos, con un puntaje de 5,02 (en una escala de 10 puntos), por debajo de Bogotá $(8,13)$, Antioquia $(6,55)$, Caldas $(6,06)$, Santander $(5,86)$, Valle del Cauca $(5,44)$, Risaralda $(5,44)$, Cundinamarca $(5,38)$, y Atlántico $(5,26)$. Con respecto al mismo estudio realizado en 2014, Boyacá permaneció en la misma posición; sin embargo, mejoró la puntuación, que para ese año estaba en 4,85 puntos (Consejo Privado de Competitividad y Universidad del Rosario, 2015). De acuerdo con este informe, una de las falencias en materia de competitividad es el grado de innovación, que involucra aspectos relacionados con: i) investigación, ii) inversión en ciencia tecnología e innovación (CTI) y patentes y iii) dinámica empresarial. En este ítem, Boyacá ocupa el puesto 13. Aun cuando, revisando los informes de competitividad de años anteriores, el departamento ha mostrado una notable mejoría, permanecen brechas que exigen un esfuerzo conjunto de las diferentes instituciones regionales para mejorar los niveles competitivos de Boyacá. Por lo tanto, se deben asegurar condiciones básicas de desarrollo local, teniendo en cuenta que el entorno es un elemento clave en la sostenibilidad de las regiones.

Por otra parte, se destacan aspectos favorables en materia de competitividad en Boyacá, relacionados con el desempeño en educación básica y media que posiciona al departamento en el puesto 2 a nivel nacional. Igualmente, su desempeño en educación superior lo ubica en el puesto 5. Los anteriores resultados se evidencian en el buen desempeño en las pruebas saber SABER, la cobertura educativa y la baja deserción escolar.

En lo correspondiente al sector del transporte los resultados no son favorables, ya que Boyacá ocupa el puesto 16 entre 25 con los siguientes resultados:

4 El índice Departamental de Competitividad evalúa la competitividad territorial a partir de tres factores: i) condiciones básicas, ii) eficiencia y iii) sofisticación e innovación. Estos factores se basan en los pilares de la competitividad propuestos por la WEF. 
Tabla 2.

Indice Departamental de competitividad 2015

\begin{tabular}{|l|c|c|}
\hline & $\begin{array}{c}\text { Puntaje } \\
(\mathbf{0}-\mathbf{1 0})\end{array}$ & $\begin{array}{c}\text { Posición } \\
\text { (entre 25) }\end{array}$ \\
\hline $\begin{array}{l}\text { Índice Departamental de competitividad } \\
2015\end{array}$ & 5,02 & 9 \\
\hline Condiciones básicas & 5,90 & 7 \\
\hline Instituciones & 6,61 & 6 \\
\hline Infraestructura & 4,87 & 14 \\
\hline Tamaño del mercado & 5,86 & 9 \\
\hline Educación básica y media & 7,31 & 2 \\
\hline Salud & 5,30 & 14 \\
\hline Medio ambiente & 4,91 & 12 \\
\hline Eficiencia & 5,26 & 6 \\
\hline Educación superior y sofisticación & 6,07 & 5 \\
\hline Eficiencia de los mercados & 4,44 & 8 \\
\hline Sofisticación e Innovación & 3,10 & 13 \\
\hline Sofisticación y diversificación & 5,10 & 13 \\
\hline Innovación y dinámica empresarial & 1,10 & 13 \\
\hline
\end{tabular}

Nota. Tomada de Informe nacional de competitividad 2015-2016, por Consejo Privado de Competitividad, 2015

Tabla 3.

Competitividad del Boyacá en el tema de transporte

\begin{tabular}{|l|c|}
\hline Ítem & $\begin{array}{c}\text { Puesto } \\
\text { entre 25 }\end{array}$ \\
\hline Transporte & 16 \\
\hline $\begin{array}{l}\text { Red vial primaria pavimentada por cada 100.000 } \\
\text { habitantes }\end{array}$ & 6 \\
\hline Red vial primaria pavimentada por área & 7 \\
\hline Porcentaje de vías pavimentadas en buen estado & 17 \\
\hline Costo de transporte terrestre a puertos & 21 \\
\hline Costo de transporte terrestre a mercado interno & 11 \\
\hline Pasajeros movilizados vía aérea & 25 \\
\hline Población conectada vía aérea & 21 \\
\hline
\end{tabular}

Nota. Tomada de Informe nacional de competitividad 2015-2016, por Consejo Privado de Competitividad, 2015.

En lo concerniente al tema de transporte de pasajeros por carretera, los indicadores que más preocupan corresponden al porcentaje de vías pavimentadas en buen estado, ítem en el que Boyacá se ubica en el puesto 17. La infraestructura vial es un determinante clave en la competitividad del sector dado que garantiza la calidad del servicio. Cuando las vías se encuentran deterioradas, las empresas de transporte no ofrecen vehículos en excelentes condiciones, lo que afecta la prestación del servicio en materia de accesibilidad y costos de operación.

\section{El sector del transporte: tendencias y desafíos}

Una vez realizada la presentación de las generalidades de la competitividad, que sirve como preámbulo al tema específico de la competitividad del transporte intermunicipal de pasajeros por carretera en Boyacá, es importante conocer las tendencias y desafíos en el nivel internacional, nacional y departamental. El desafío quizás más importante es el del cambio que involucra acciones tendientes a garantizar un transporte moderno, ágil, seguro y cómodo, para el ciudadano; rentable para los empresarios; y fuente generadora de trabajo digno y profesionalizado.

Considerando lo anterior, cabe resaltar que el sector transporte, en sus diferentes dimensiones, desempeña un papel importante en la consolidación de los procesos de globalización y de competitividad en la sociedad. El transporte es un eje transversal que contribuye a mejorar la competitividad de los demás sectores económicos, dada su importancia y trascendencia en la realización de las diferentes actividades de la sociedad en general. Se está presenciando, en este sentido, una transformación dentro del sector debido a factores como el crecimiento de la población que invita a considerar los parámetros de la prestación del mismo (Tobón, 2009).

En conclusión, el llamado para los empresarios del transporte intermunicipal de pasajeros es a estar vigilantes a las mutaciones del entorno que fijan nuevos parámetros en la prestación del servicio con criterios de calidad, exigencia de los usuarios, comodidad, agilidad y seguridad.

\section{Algunas tendencias a nivel internacional}

En el contexto internacional, el tema del transporte de pasajeros ha sido de trascendental importancia por el impacto económico y social que genera el transporte en la sociedad. La movilidad es una necesidad básica de la vida del siglo xxI, un servicio que permite acceder al trabajo, los mercados, la educación, la sanidad, otros primarios, y el ocio. Son diferentes las necesidades y las condiciones bajo las cuales el servicio de transporte de pasajeros debe prestarse, dado que no existe actualmente, ni existirá en un futuro, un sólo modo de movilidad capaz de satisfacer todas 
las necesidades de los pasajeros. Lo anterior se explica por aspectos como el crecimiento poblacional, el calentamiento global, el cambio de hábitos y costumbres, entre otros, que obligan a los diferentes actores de la cadena del transporte a revaluar continuamente las políticas del sector (Meyer, 2003).

Quizá uno de los cambios más influyentes en los modos de movilidad está dado por el crecimiento vertiginoso de las ciudades que ha dado lugar a la formulación de proyectos de movilidad sostenible, limpia y energéticamente eficiente. En este sentido, resulta oportuno resaltar que las políticas del transporte de pasajeros deben ser reconsideradas continuamente, más aún cuando se espera que a finales del siglo xxi la población mundial sea de unos 11000 millones de habitantes (Centro de Noticias onu, 2011), ante lo cual Wolfang Meyer, presidente de la Unión Internacional de Transporte Público (UITP) ${ }^{5}$, en el Congreso celebrado en Madrid en 2005, refiriéndose a la sostenibilidad del transporte, afirma:

El transporte público en el mundo se encuentra en un momento crucial de su desarrollo, con tendencias de gran magnitud como son el crecimiento urbano, los cambios demográficos y de estilo de vida, la globalización de la economía y el acceso generalizado a nuevas tecnologías que afectan cada vez más a nuestro sector. Ahora es cuando debemos ser proactivos e identificar una serie de soluciones específicas a fin de que el sector tenga las armas para afrontar de manera efectiva estos retos en el futuro (citado en Colmenares, 2007, p. 2).

Además de esta reflexión, la UiTp establece lo que denominó las "tres paradas" para el transporte público sostenible:

- Equidad social: la primera línea de acción. Hace hincapié en los aspectos sociales y en el rol que desempeña la movilidad en la calidad de vida de las personas. Describe los retos con los que se enfrenta el mundo a fin de proporcionar una movilidad sostenible para todos teniendo en cuenta aspectos de carácter social como el aumento de la población urbana.

Fundada en 1885, es la organización que reúne a las autoridades del sector del transporte público, los operadores, los grupos de toma de decisiones, las organizaciones científicas, los proveedores de equipos y los industriales. Es una plataforma para la cooperación mundial y para el intercambio del conocimiento entre 2500 miembros y 80 países.
- Equilibrio medioambiental: el medio ambiente y el estado del planeta se consideran el segundo pilar del desarrollo sostenible del transporte. Este examina el impacto del consumo de energía, y otros recursos no renovables como el uso del territorio, en el equilibrio ecológico y los efectos que resultan de ello en el marco del calentamiento global del planeta. Esto es, la preocupación por el aumento constante del consumo de hidrocarburos que provoca un incremento de las emisiones de dióxido de carbono con el consiguiente efecto sobre el clima.

- Valor económico: el coste de la movilidad para la sociedad es sumamente importante y este pilar se refiere a cómo pueden reducirse los costes de transporte y confrontarse los retos económicos debidos a la congestión. Así mismo se refiere a los beneficios de la movilidad sostenible en las economías locales al crear empleo y contribuir a la cohesión social. El transporte público se considera de utilidad pública, ya que tiene un rol primordial en la productividad regional $y$, por ende, la de sus actividades económicas y sociales.

El escenario natural para el debate del transporte de pasajeros se dio en la 11th International Conference on Urban Transport and the Environment in the 21st Century, Urban Transport 2005. Allí se hicieron evidentes las preocupaciones y las tendencias del sector en el mundo: los sistemas de transporte público urbano, infraestructura y mantenimiento, seguridad y protección, sostenibilidad del transporte, accesibilidad y movilidad, impacto ambiental, contaminación de aire y el ruido, energía y combustibles (Brebbia y Longhurst, 2005). Este último asunto es de vital importancia dado que tiene un impacto sobre varios focos de atención como la sostenibilidad ambiental o el impacto económico y la disminución de la contaminación. Su importancia se evidencia con experiencias en países como Brasil, que ha introducido combustibles alternativos como el etanol y el biodiesel desde hace más de treinta años en los sistemas de transporte público (Berni, Bajav y Manduca, 2005). Igualmente, otros estudios realizados en España muestran que existe un amplio abanico de alternativas de tecnologías, en vehículos y combustibles, capaces de reducir la dependencia del petróleo y los problemas medioambientales derivados de su consumo (Fernández, Álvarez, Ortega y Martínez, 2011; Maeso, González y Pérez, 2012). 
Además de lo anterior, es evidente la preocupación por definir aspectos estratégicos para alcanzar la sostenibilidad del servicio a través de la promoción de modelos de transporte público, la restricción de carros dentro de las ciudades, el impuesto sobre el transporte ecológico, la promoción de vehículos de transporte amigables con el medio ambiente, el acceso equitativo a sistemas de transporte público, la cofinanciación de las inversiones de transporte, las políticas de planificación sustentables, el uso de mejores sistemas de comunicación y la mejor administración del servicio; aspectos que han sido denominados el "decálogo" para la estrategia de transporte urbano sostenible (Malasek y JazdzikOsmólska, 2005).

Si bien los aspectos técnicos y económicos del servicio constituyen una fuerte preocupación de los actores del sector, su aspecto político es también una preocupación reciente para los gobiernos, cada vez más cuestionados por el impacto negativo en la cotidianidad de sus pueblos. Se han dado avances importantes en cuanto a políticas para mejorar la calidad y las condiciones de vida de millones de usuarios. Tal es, por ejemplo, el caso de India, un país con una proyección importante de crecimiento de su población y una red vial en desarrollo. Allí se han implementado medidas políticas para mejorar el transporte urbano, cuyo objetivo principal es proporcionar y promover vínculos sostenibles de alta calidad para las personas, bienes y servicios, reduciendo la necesidad de viajar por medios personalizados y aumentando la demanda del sistema de transporte público. Estimular el uso de combustibles limpios y restringir el uso de vehículos contaminantes son parte de las acciones que el gobierno ha llevado a cabo en las ciudades más congestionadas del país (Pucher, Korattyswaroopam y Ittyerah, 2004). Ciudades como Grenoble (Francia), Génova (Italia), Darlington (Reino Unido), Burgos (España), Aalborg (Dinamarca), entre otras $10 \mathrm{de}$ toda Europa, han implementado medidas para mejorar la movilidad. Estas medidas tienen que ver con estrategias integradas para varios sistemas de transporte como ciclo vías, rutas de tren; igualmente, con mejoras en la seguridad y el mantenimiento vial; información en tiempo real; control de accesos; parqueaderos, etcétera (Monzón y López, 2009). Para implementar estas medidas lo importante es el compromiso del gobierno y, por supuesto, la educación de la sociedad.

\section{El sector del transporte de pasajeros en Colombia.}

En Colombia, se define el servicio intermunicipal de pasajeros como la movilización de personas de un punto de origen hacia un destino específico, dentro o fuera de un municipio o departamento, realizada por organizaciones empresariales de carácter público o privado de orden municipal, departamental o nacional. En Colombia, la regulación del sistema de transporte, en general, comienza en 1996 a través de la Ley $336,{ }^{6}$ la cual ha sido reformada paulatinamente en virtud de las modificaciones a la estructura del Estado colombiano derivadas de la Constitución Política de 1991 (como la Ley 489 de 1998 y la Ley 790 de 2002). Específicamente, ha habido una reforma con la creación del Ministerio de Transporte, cuyo enfoque misional es garantizar el desarrollo y mejoramiento del transporte, tránsito y su infraestructura, de manera integral, competitiva y segura (Mintransporte, 2015).

El sector del transporte intermunicipal de pasajeros en Colombia ha contribuido al desarrollo económico y social de las regiones en función de las necesidades de la población y del sector empresarial. Igualmente, el sector se organiza a partir de las terminales de transporte en las ciudades, las cuales facilitan la operación del servicio (Aktivia Servicios Financieros, 2003). El sector atraviesa, no obstante, una serie de dificultades derivadas de situaciones como la intensificación de la competencia del transporte aéreo, la creciente compra de vehículos por parte de las familias y el rezago en la infraestructura vial, cuyo indicador en obras civiles relacionadas con carreteras en 2013-I solo se incrementó el 1,4\%. Sin embargo, indica la fuente recién citada que el sector logra salir adelante por la diversificación en sus servicios, por ejemplo, como corresponsales no bancarios, transporte de mercancía y servicios de comunicación en sus puntos de venta. Otros logros de las empresas del sector están relacionados con el cubrimiento de

6 Esta norma tiene por objeto unificar los principios y los criterios que servirán de fundamento para la regulación y reglamentación del transporte público aéreo, marítimo, fluvial, férreo, masivo, terrestre y su operación en el territorio nacional de conformidad con la Ley 105 de 1993 y con las normas que la modifiquen o sustituyan. Aunque en esta norma no se separa el transporte de pasajeros del de carga, sí se señalan bases legales importantes como la regulación para la creación de las empresas de transporte público, la prestación del servicio, conexiones, tarifas, entre otros aspectos. 


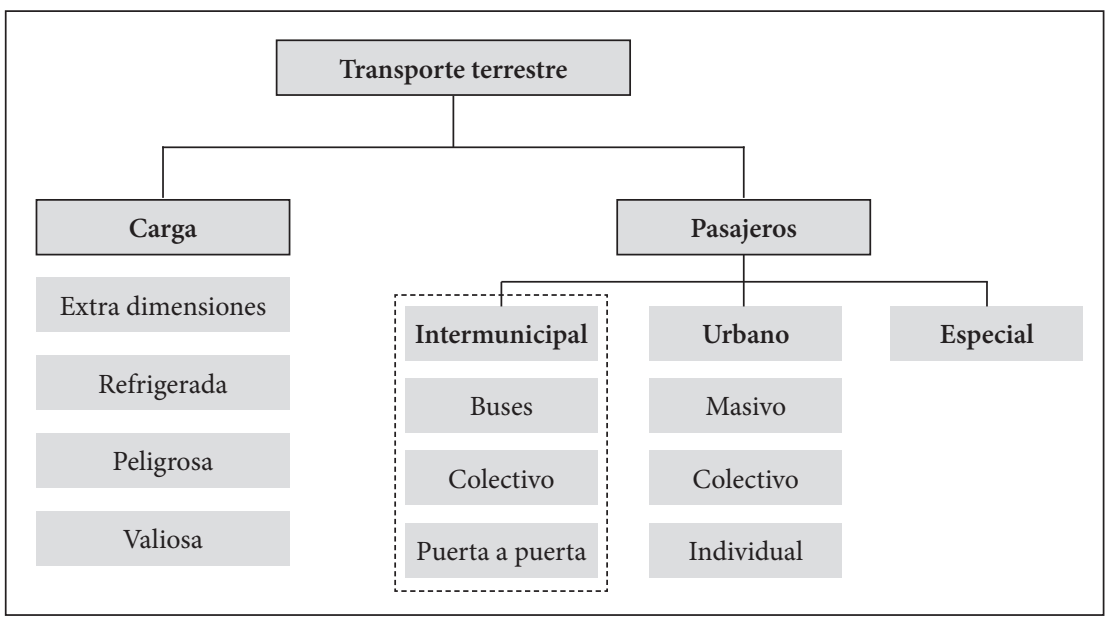

Figura 4. Cadena del transporte. Tomada de Estudios sectoriales. El transporte terrestre de pasajeros, por Aktivia Servicios Financieros, 2013.

trayectos en los que el transporte aéreo es muy costoso o inexistente.

Para el 2012, según informe sectorial de la Asociación Nacional de Industriales (ANDI) 519 empresas conformaban el sector transporte terrestre de pasajeros (de las cuales el $57 \%$ eran sociedades comerciales y el $43 \%$ pertenecían al sector cooperativo). Estas operaban en el mercado a través de los permisos de operación concedidos por el Ministerio de Transporte para prestar el servicio en una ruta determinada, por término indefinido y bajo un régimen de libertad tarifaria con precios mínimos establecidos periódicamente por el Ministerio de Transporte. Cundinamarca era el departamento con mayor número de empresas (63\%), incluyendo Bogotá. Antioquia representaba el 15,2\% de las empresas del país.

Las empresas de transporte habilitadas bajo la modalidad de servicio intermunicipal son vigiladas subjetiva y objetivamente por la Superintendencia de Puertos y Transporte, su actividad se encuentra regulada por los postulados generales de la Ley 105 de 1993 y la Ley 336 de 1996. Los requisitos de acceso al servicio y operación han sido definidos en el Decreto 171 de 2001. La flota vehicular de transporte intermunicipal era de 38.882 vehículos, de los cuales el $48 \%$ correspondía a autobuses con capacidad para 32 o más pasajeros. En el 2011 se movilizaron 126338107 pasajeros en 12798114 frecuencias (Cámara Sectorial de Transporte ANDI, 2012).

En Colombia, la cadena del transporte se organiza en servicios de carga y pasajeros. Este último tipo dividido en tres clases de servicio (intermunicipal, urbano y especial), cada uno con un normatividad específica del Ministerio de Transporte, entidad que fija los criterios de operación de acuerdo al alcance del servicio prestado.

\section{Régimen jurídico del transporte de pasajeros por carretera en Colombia}

La prestación del servicio público de transporte terrestre en Colombia, que constitucionalmente es inherente a la finalidad social del estado, ha sido delegada por este a los particulares. En el marco de esta delegación, ejerce una intervención en la operación a través de la regulación, control y vigilancia para asegurar una adecuada prestación en términos de calidad, seguridad y eficiencia. Para el cumplimiento de la regulación, el sector de transporte de pasajeros cuenta con un conjunto de normas que permiten establecer las políticas de prestación del servicio. Dichas normas son presentadas en la tabla 4.

A pesar del conflicto armado vivido en Colombia desde hace muchos años, y neutralizado en los anteriores periodos de gobierno presidenciales, el transporte terrestre de pasajeros no se queda estático frente a las aerolíneas de bajo costo. Actualmente, viajar por tierra es más seguro que en épocas anteriores, en las que la inseguridad frenó el crecimiento de las inversiones por las constantes pérdidas en quema de buses, carreteras cerradas por orden público y derrumbes. Pero el panorama cambió y las empresas están retomando el camino de la modernización. 
Tabla 4

Normatividad relacionada con la prestación del servicio de transporte de pasajeros en Colombia

\begin{tabular}{|c|c|}
\hline DECRETO O LEY & OBJETO \\
\hline Decreto 171 de 2001 & $\begin{array}{l}\text { Reglamenta la habilitación de las empresas de transporte público terrestre automotor de pasajeros por } \\
\text { carretera y la prestación por parte de estas de un servicio eficiente, seguro, oportuno y económico bajo los } \\
\text { criterios básicos de cumplimiento de los principios rectores del transporte, como la libre competencia y la } \\
\text { iniciativa privada, a las cuales solamente se aplicarán las restricciones establecidas por la Ley y los Conve- } \\
\text { nios Internacionales (Presidencia de la República de Colombia, 2001). }\end{array}$ \\
\hline Decreto 1485 de 2002 & $\begin{array}{l}\text { Reglamenta el Fondo Nacional de Reposición y Renovación del Parque Automotor de Servicio Público de } \\
\text { Transporte Terrestre de Pasajeros, el cual es un ente con personería jurídica, de naturaleza mixta, que en lo } \\
\text { no previsto en este decreto se regirá por las normas del derecho privado. El objeto del Fondo es atender los } \\
\text { requerimientos económicos y financieros para la reposición y renovación del parque automotor de los vehí- } \\
\text { culos de servicio de transporte público colectivo terrestre de pasajeros con radio de acción metropolitano o } \\
\text { urbano (Presidencia de la República de Colombia, 2002). }\end{array}$ \\
\hline $\begin{array}{l}\text { Decreto número } 0491 \\
\text { de } 1996\end{array}$ & $\begin{array}{l}\text { Se establecen condiciones técnicas del servicio de transporte terrestre de pasajeros. Las condiciones son: } \\
\text { homologación automática, revisión técnico-mecánica, licencias de conducción y certificado de movilización } \\
\text { (Presidencia de la República de Colombia, 1996). }\end{array}$ \\
\hline $\begin{array}{l}\text { Decreto número4668 } \\
\text { de } 2006\end{array}$ & $\begin{array}{l}\text { Se establecen unas disposiciones relacionadas con el capital pagado o patrimonio líquido de las empresas } \\
\text { asociativas del sector solidario o cooperativas de transporte terrestre automotor (Presidencia de la Repú- } \\
\text { blica de Colombia, 2006). }\end{array}$ \\
\hline CONPES 3260 de 2003 & $\begin{array}{l}\text { Presenta la política del Gobierno nacional para impulsar la implantación de sistemas integrados de trans- } \\
\text { porte masivo - SITM - en las grandes ciudades del país y fortalecer la capacidad institucional para planear } \\
\text { y gestionar el tráfico y transporte en las demás ciudades con el propósito de incrementar su calidad de vida } \\
\text { y productividad, e impulsar procesos integrales de desarrollo urbano dentro de un marco de eficiencia fiscal } \\
\text { que promueva nuevos espacios para la participación del sector privado en el desarrollo y operación del } \\
\text { transporte urbano de pasajeros (Departamento Nacional de Planeación, 2003). }\end{array}$ \\
\hline $\begin{array}{l}\text { Resolución } 3600 \text { de } \\
2001\end{array}$ & $\begin{array}{l}\text { Se establece libertad tarifaria para la prestación de servicio público de transporte terrestre intermunicipal de } \\
\text { pasajeros por carretera (Ministerio de Transporte, 2001). }\end{array}$ \\
\hline $\begin{array}{l}\text { Resolución } 3600 \text { de } \\
2001\end{array}$ & $\begin{array}{l}\text { Se fijan las tarifas mínimas para la prestación del servicio público de transporte terrestre automotor de } \\
\text { pasajeros por carretera (Ministerio de Transporte, 2001). }\end{array}$ \\
\hline
\end{tabular}

Nota. Elaboración propia.

Gustavo Gallo Machado, en un artículo publicado en el periódico El Colombiano, hace una síntesis de los últimos avances en materia de transporte de pasajeros que refleja claramente las tendencias innovadoras de algunas de las empresas más representativas del país. Una de estas organizaciones invirtió en vehículos innovadores 19000 millones de pesos en un año. Además, el sector del transporte terrestre de pasajeros viene implementado soluciones tecnológicas de seguimiento que mejoran la seguridad y confiabilidad del servicio (Gallo, 26 de agosto de 2012). Ejemplo de lo anteriormente mencionado es la ventaja tecnológica en el servicio que permite a un familiar de un pasajero consultar en tiempo real, ingresando a la página web de la empresa de transporte, en qué lugar del camino se encuentra el pasajero, la velocidad a que avanza el bus y la hora a la que llegará a la ciudad de destino.

\section{El reto del sector del transporte de pasajeros}

Es importante sensibilizar a los pasajeros acerca de la formalidad como garantía de calidad y seguridad en el servicio. Los servicios informales de transporte, a pesar de ofrecer un precio más bajo, no ofrecen las condiciones adecuadas de un buen servicio.

Como una necesidad para el desarrollo de sistemas de transportes amigables con el medio ambiente se crea el documento CONPEs 3260 en el 2003. Este busca impulsar la implementación de sistemas integrados de transporte masivo - SITM - en las grandes ciudades del país y fortalecer la capacidad institucional para planear y gestionar el tráfico y transporte en las demás ciudades con el propósito de incrementar su calidad de vida y productividad e impulsar procesos integrales de desarrollo urbano dentro de un marco de eficiencia fiscal que promueva nuevos espacios 
para la participación del sector privado en el desarrollo y la operación del transporte urbano de pasajeros.

El Documento CONPes 3260 de 2003 resume la problemática del transporte de pasajeros de la siguiente forma:

El esquema empresarial existente es ineficiente al promover la competencia de los operadores en las vías recogiendo pasajeros (competencia en el mercado) y no por las rutas que prestarían el servicio bajo unos parámetros de calidad y servicio preestablecidos (competencia por el mercado). La autoridad local otorga permisos a las Empresas de Transporte Público para operar las rutas y éstas, a su vez, afilian los vehículos requeridos, sin ejercer mayor control durante la prestación del servicio y devengan de acuerdo a la cantidad de afiliados. Los propietarios de dichos vehículos afiliados perciben una renta fija por parte de los conductores, quienes ganan por pasajero recogido, provocando lo que comúnmente se conoce como la "guerra del centavo" [...] Además de congestión, bajo este modelo el conductor no tiene estímulos claros para mejorar la técnica de conducción con el fin de minimizar incidentes que ponen en riesgo a los pasajeros, sino lo contrario. Según el Fondo de Prevención Vial, cerca del $40 \%$ de los accidentes de tránsito urbano involucran vehículos de transporte público (Departamento Nacional de Planeación, 2003, p. 6).

La ineficiente operación del transporte público trae importantes afectaciones en la calidad de vida y la productividad urbana. Por ejemplo, la congestión reduce sensiblemente la productividad de la economía urbana; la contaminación ambiental genera efectos nocivos a nivel local e incluso global; y los accidentes implican pérdidas de vidas y daños a la salud y a la propiedad de las personas. Según este documento, de persistir la situación actual del transporte público colectivo de pasajeros, sus deficiencias seguirán limitando los niveles de productividad urbana y de calidad de vida en las grandes ciudades. Por ello, el reto de las ciudades colombianas es reducir la tendencia a la utilización ineficiente del automóvil particular, promoviendo que la movilidad de las personas se fundamente en la utilización de los vehículos de transporte público y en los vehículos y modos de transporte no motorizados.

Lo anterior explica la implementación de Sistemas Integrados de Transporte en las grandes ciudades, como una alternativa limpia que aporta al cuidado del medio ambiente. Estos sistemas siguen una de las tendencias mundiales descritas por Wolfang Meyer, presidente de la UITP, respecto a las "tres paradas" del transporte ya mencionadas.

\section{Sector de transporte de pasajeros en Boyacá}

En el 2014, el Centro Regional de Gestión para la Productividad y la Innovación de Boyacá CREPIB, junto con la Universidad Pedagógica y Tecnológica de Colombia, llevó a cabo el estudio Análisis de las brechas competitivas del sector transporte intermunicipal de pasajeros en Boyacá con el propósito de brindar al sector una información clara, coherente y actualizada de la competitividad. Esto con el fin de facilitar a los actores de la cadena del transporte herramientas para la formulación de estrategias conducentes a la sostenibilidad del transporte intermunicipal de pasajeros por carretera (Rodríguez y Becerra, 2014). En la siguiente tabla se muestran algunos resultados de este estudio realizado a 20 de las 25 empresas, registradas en la base de datos de la Superintendencia de Puertos y Transportes, operadoras del servicio de transporte de pasajeros en el departamento.

Tabla 5

Características del Transporte de Pasajeros en Boyacá

\begin{tabular}{|l|l|}
\hline \multicolumn{1}{|c|}{ INDICADOR } & \multicolumn{1}{c|}{ RESULTADO } \\
\hline Número de empresas encuestadas & 20 \\
\hline Tamaño de las empresas & Grande, 15\%. Pequeña, 35\%. Mediana, 15\%. Micro, 35\%. \\
\hline Tipo de empresa & $\begin{array}{l}\text { Cooperativa, 60\%. Sociedad anónima, 25\%. Sociedad } \\
\text { limitada, 10\%. Persona Natural 5\%. }\end{array}$ \\
\hline Total de vehículos & 1505 \\
\hline
\end{tabular}




\begin{tabular}{|c|c|c|}
\hline INDICADOR & \multicolumn{2}{|l|}{ RESULTADO } \\
\hline Distribución del parque automotor & \multicolumn{2}{|l|}{$\begin{array}{l}\text { Grupo A: } 21 \% \\
\text { Grupo B: } 57 \% \\
\text { Grupo C: } 22 \%\end{array}$} \\
\hline Distribución de edad del parque automotor & \multicolumn{2}{|l|}{$\begin{array}{l}\text { 1980-1990: } 6 \% \\
\text { 1991-2000: } 16 \% \\
\text { 2001-2005: } 19 \% \\
\text { 2006-2010: } 46 \% \\
\text { 2011-2014: } 13 \%\end{array}$} \\
\hline \multirow{8}{*}{ Ponderación, por parte de los empresarios, de los factores de calidad } & Estado físico del vehículo & MUY ALTO \\
\hline & Trato al usuario & MUY ALTO \\
\hline & Presentación del conductor & ALTO \\
\hline & $\begin{array}{l}\text { Forma de operación del vehículo por } \\
\text { parte del conductor }\end{array}$ & ALTO \\
\hline & $\begin{array}{l}\text { Tiempo de espera del pasajero en el } \\
\text { vehículo }\end{array}$ & MEDIO \\
\hline & Información de rutas y paradas & MEDIO \\
\hline & Tarifa de transporte & BAJO \\
\hline & Servicios adicionales & BAJO \\
\hline Número de empresas certificadas con Iso 9001 & \multicolumn{2}{|l|}{2} \\
\hline Número de empresas certificadas con Iso 14001 & \multicolumn{2}{|l|}{1} \\
\hline Número de empresas en proceso de certificación Iso 9001 & \multicolumn{2}{|l|}{6} \\
\hline Número de empresas en proceso de certificación Iso 14001 & \multicolumn{2}{|l|}{1} \\
\hline \multirow{4}{*}{ Estrategias de mejoramiento continuo } & Renovación parque automotor & $31 \%$ \\
\hline & $\begin{array}{l}\text { Atención al cliente } \\
\text { Capacitación }\end{array}$ & $\begin{array}{l}29 \% \\
17 \% \\
\end{array}$ \\
\hline & Mejoramiento continuo & $14 \%$ \\
\hline & Cumplimiento de normatividad & $9 \%$ \\
\hline Porcentaje de empresas que aplican protocolos de servicio & \multicolumn{2}{|l|}{$60 \%$} \\
\hline Número de personas que laboran en el sector & \multicolumn{2}{|l|}{2943} \\
\hline Número de conductores & \multicolumn{2}{|l|}{2338} \\
\hline Número de hombres & \multicolumn{2}{|l|}{2327} \\
\hline Número de mujeres & \multicolumn{2}{|l|}{11} \\
\hline Número de personal administrativo & \multicolumn{2}{|l|}{416} \\
\hline Número de hombres & \multicolumn{2}{|l|}{190} \\
\hline Número de mujeres & \multicolumn{2}{|l|}{226} \\
\hline Auxiliares de venta & \multicolumn{2}{|l|}{107} \\
\hline Número de hombres & \multicolumn{2}{|l|}{55} \\
\hline Número de mujeres & \multicolumn{2}{|l|}{52} \\
\hline Auxiliares de servicio & \multicolumn{2}{|l|}{82} \\
\hline Número de hombres & \multicolumn{2}{|l|}{71} \\
\hline Número de mujeres & \multicolumn{2}{|l|}{11} \\
\hline
\end{tabular}




\begin{tabular}{|l|l|}
\hline \multicolumn{1}{|c|}{ INDICADOR } & \multicolumn{1}{c|}{ RESULTADO } \\
\hline & Primaria: $5 \%$ \\
Nivel de formación de los gerentes & Bachiller: $15 \%$ \\
& Tecnológico: $10 \%$ \\
& Técnico: $5 \%$ \\
Universitario: $60 \%$ \\
\hline Número de empresas con página web & Especialización: $5 \%$ \\
\hline
\end{tabular}

Nota. En distribución del parque automotor, Grupo A = Vehículos con capacidad de 4 a 9 pasajeros. Automóvil, zampero, camioneta; Grupo B = Vehículos con capacidad de 10 a 19 pasajeros. Microbús; Grupo C = Vehículos con capacidad para más de 19 pasajeros. Tomado de "Competitividad del sector transporte intermunicipal de pasajeros en Boyacá", por D. Rodríguez y C. Becerra, en Inquietud Empresarial, XIV(2), 2014.

Realizando una revisión de literatura en las bases de datos electrónicas, se evidencia que solamente existe un estudio de competitividad de transporte intermunicipal de pasajeros en Boyacá, desarrollado por Rodríguez y Becerra (2014). Lo anterior da cuenta del vacío enorme que existe en la materia, lo cual genera preocupación, pero, al mismo tiempo, nos ofrece la oportunidad de continuar en el fortalecimiento de la investigación en el sector de transporte que contribuye al desarrollo del departamento.

Por otra parte, en la tabla 6 se detallan los resultados de la revisión de tesis, disponibles en el catálogo en línea del servicio de biblioteca de la Universidad Pedagógica y Tecnológica de Colombia, en temas relacionados con el transporte terrestre de pasajeros.

Tabla 6

Estudios relacionados con el transporte de pasajeros, según sistema de Bibliotecas UPTC Tunja

\begin{tabular}{|c|c|c|c|}
\hline TEMAS & $\begin{array}{l}\text { No. de } \\
\text { Tesis }\end{array}$ & Porcentaje & SUBTEMAS \\
\hline Caracterización sectorial & 2 & $1,77 \%$ & Diagnostico sectorial a partir de modelos de gestión. \\
\hline Estudios técnicos & 44 & $38,94 \%$ & $\begin{array}{l}\text { Reorganización y optimización de sistemas de transporte, tiempos de viaje, } \\
\text { manuales, necesidades de movilización, estudios de rutas (modelos, reestruc- } \\
\text { turación, cobertura), movilización de pasajeros, racionalización del transporte, } \\
\text { estudios de operación, infraestructura y movilidad, modelación urbana, diseño } \\
\text { de terminales, planes operativos, sistemas de información. }\end{array}$ \\
\hline Oferta y demanda & 24 & $21,24 \%$ & Investigaciones de mercado, diagnósticos de oferta y demanda de rutas. \\
\hline Planes de mercadeo & 5 & $4,42 \%$ & $\begin{array}{l}\text { Planes de mercadeo de empresas y terminales de transporte. Plan de mercadeo } \\
\text { de transporte férreo de pasajeros. }\end{array}$ \\
\hline Análisis financiero & 6 & $5,31 \%$ & $\begin{array}{l}\text { Estudios de costos de operación, diseño de programas financieros, estudios } \\
\text { tributarios y análisis financiero }\end{array}$ \\
\hline Estudios de factibilidad & 22 & $19,47 \%$ & Estudios de factibilidad para la creación de empresas y creación de nuevas rutas. \\
\hline $\begin{array}{l}\text { Dimensión social del } \\
\text { transporte }\end{array}$ & 1 & $0,88 \%$ & Enfoque de la comunicación social. \\
\hline Percepción de calidad & 3 & $2,65 \%$ & Criterios de tarifa, comodidad y calidad. \\
\hline $\begin{array}{l}\text { Creación de departamentos } \\
\text { organizacionales }\end{array}$ & 2 & $1,77 \%$ & Creación de nuevas áreas funcionales. \\
\hline Ajuste a la normatividad & 1 & $0,88 \%$ & Agilidad para realización de trámites. \\
\hline $\begin{array}{l}\text { Implementación de siste- } \\
\text { mas de gestión de calidad }\end{array}$ & 1 & $0,88 \%$ & Implementación Iso 9001. \\
\hline Competitividad & 1 & $0,88 \%$ & Región económica de planificación (Corredor industrial Tunja, Duitama y Sogamoso). \\
\hline $\begin{array}{l}\text { Responsabilidad social } \\
\text { empresarial }\end{array}$ & 1 & $0,88 \%$ & Políticas de responsabilidad social a través del cuadro de mando integral. \\
\hline Total & 113 & $100,00 \%$ & \\
\hline
\end{tabular}

Nota. Elaboración propia. 
Se observa en la anterior tabla que los estudios relacionados con el transporte de pasajeros, realizados por la UPTC ${ }^{7}$, son, en su mayoría, estudios técnicos. Específicamente, son estudios de movilidad, diseños de ruta, diseño de infraestructura para el transporte como terminales de transporte, entre otros. Son investigaciones que, de cierta manera, contribuyen a incrementar la productividad del sector, pero que no abordan temas como la competitividad, calidad, atención al cliente, innovación en el servicio, sobre lo que poco o nada se dicho. En consecuencia, la competitividad del transporte es un tema que se debe abordar de forma más amplia e integral, es decir, se debe involucrar el estudio el conjunto de elementos clave de entornos competitivos de acuerdo con las teorías y modelos existentes.

Recientes avances del sector transporte intermunicipal de pasajeros

\section{Construcción y funcionamiento de la terminal de Duitama}

La nueva terminal de transportes de Duitama tuvo una inversión cercana a los 20000 millones de pesos y es una de las construcciones más modernas del oriente colombiano. Cuenta con salas de espera; 65 locales comerciales, entre ellos entidades financieras, cajeros automáticos, una plazoleta de comidas; zona de encomiendas; vías exclusivas para la circulación de busetas y taxis de servicio urbano oratorio; un área administrativa; llegada y zona VIP; así como consultorios para medicina preventiva y alcoholimetría para conductores (Boyacá Sie7e Días, 2015).

\section{Construcción Nueva Terminal de Tunja}

Actualmente, se encuentra en construcción la Nueva Terminal de Transportes de la ciudad de Tunja, debido que la infraestructura actual es considerada una de las atrasadas de Colombia. El predio donde se levanta la terminal tiene una extensión aproximada de 59.000 metros cuadrados. El área construida cubierta tendrá dos niveles: un nivel inferior de 4.759 metros cuadrados y uno superior de 5.718. Las áreas operacionales exteriores tendrán 37.871 metros cuadrados. Este inmueble dispondrá además de accesos

Única institución que ofrece el programa de Ingeniería de Vías y Transportes a nivel nacional, según el Sistema Nacional de Información de la Educación Superior (SNIEs). peatonales, una sala de abordaje para 2.000 pasajeros cada hora, área de taquillas y de administración, locales comerciales, baterías de baños, plazoleta de comidas, amplias zonas áreas verdes y bahías operacionales (Gobernación de Boyacá, 23 de octubre de 2013).

\section{Modernización de Parque automotor}

A partir del 2013, dos reconocidas empresas del sector del transporte intermunicipal de pasajeros han adquirido buses de segundo piso, con capacidad para 60 pasajeros, especialmente para cubrir la ruta Sogamoso - Tunja - Bogotá. Estos vehículos tienen unas especificaciones muy altas, como servicio de Wi-Fi para conectarse a Internet y 18 tomas de 110 voltios para cargar celulares u otros equipos (Boyacá Sie7e Días, 2015).

\section{Competitividad del transporte de pasajeros y políticas de mejoramiento sectorial}

Con el fin de realizar un paralelo entre la conceptualización general de la competitividad y las políticas del ámbito nacional y departamental dirigido a mejorar la competitividad del transporte intermunicipal de pasajeros por carretera en Boyacá, es necesario identificar los aspectos clave y comunes en los cuales se enmarca el concepto de competitividad. La revisión de literatura da cuenta de la competitividad como un factor de sostenibilidad de las empresas, los sectores económicos y los territorios que redunda en las capacidades de los mismos de mantenerse en un entorno cada vez más exigente. La productividad resulta ser un elemento clave para el fortalecimiento competitivo de las organizaciones dado que permite estandarizar costos de transacción y de capital, así como generar capacidades de innovación a través de la incorporación de tecnologías.

Las políticas de los Gobiernos nacional y departamental en materia de competitividad se han enfocado en la necesidad de potenciar los territorios mediante el impulso de la productividad propiciada por las condiciones favorables de sostenibilidad que contribuyen al mejoramiento de la calidad de vida. Con este propósito, el Gobierno nacional consolida la política de competitividad contemplada en el documento cONPES 3527 de 2008 que se sustenta en cinco pilares: 1) desarrollo de sectores o clúster de clase mundial, 2) salto en la productividad y el empleo, 3) formalización 
empresarial y laboral, 4) fomento a la ciencia, la tecnología y la innovación, y 5) estrategias transversales de promoción de la competencia y la inversión. Dentro de la construcción de la política de competitividad, se establecen 15 planes de acción en diferentes áreas, enmarcados en los pilares anteriormente mencionados (Departamento Nacional de Planeación, 2008). Uno de estos planes se enfoca en el tema de logística y transporte. Su objetivo es solucionar las deficiencias identificadas en la financiación de proyectos de infraestructura, regulación y normatividad asociadas al transporte y la logística. Para ello, se incluyen cinco estrategias: financiación privada en infraestructura, regulación del transporte de carga, fortalecimiento del marco regulatorio de la infraestructura, política nacional de logística, priorización de proyectos estratégicos de infraestructura y logística para la competitividad.

Como se puede evidenciar, la política de competitividad, en lo concerniente al transporte, se basa en el mejoramiento de la infraestructura, esto es, en medidas como la construcción de carreteras y el fortalecimiento de la regulación de esta actividad. Este plan no se hace énfasis en el fortalecimiento de otros modos de transporte diferentes al de carga, como, por ejemplo, el transporte de pasajeros. Igualmente, es importante mencionar que la competitividad se refleja en la infraestructura - que por supuesto es importante-, dejando a un lado otros factores como el aseguramiento de la calidad en la prestación de los servicios mediante la preparación de los operadores de transporte para enfrentar las nuevas exigencias planteadas por los procesos de globalización. Por otra parte, acerca del documento CONPEs 3260 de 2003, el cual busca impulsar la implantación de sistemas integrados de transporte masivo en las grandes urbes de Colombia, se puede afirmar que fija un punto de partida para la articulación de sistemas de transporte intermunicipal con los sistemas masivos de las principales ciudades (Departamento Nacional de Planeación, 2003). En consecuencia, deben existir políticas estructuradas de acuerdo con las condiciones del entorno que propendan por la integración y transformación de la sociedad, tal como lo específica una de las premisas la competitividad sistémica.

La competitividad ha representado una preocupación para el Gobierno colombiano, que, a través de acciones contempladas en los planes de desarrollo, busca dinamizar la actividad económica nacional. Esto con el fin de mejorar la calidad de vida de los conciudadanos y, al mismo tiempo, lograr una ubicación más competitiva del país en el mundo.
Precisamente por esto, en el plan de desarrollo Todos por un nuevo país, 2014-2018, del actual gobierno, se establece como una de las estrategias la competitividad y la infraestructura estratégica que integra a todos los sectores (Gobierno de Colombia, 2014).

En materia de transporte de pasajeros, el Plan Nacional de Desarrollo actual hace énfasis en la competitividad del sector a través de la sostenibilidad, la cual radica en la financiación para la reposición y mantenimiento de los equipos. Asimismo, incentiva la incorporación de tecnologías limpias y la accesibilidad a los vehículos para personas con movilidad reducida; e, igualmente, promueve estrategias de articulación y fomento de la movilidad en medios no motorizados, implementación de sistemas de recaudo, información y control de flota que garanticen la sostenibilidad del sistema.

En Boyacá, han existido acciones que buscan el mejoramiento de la competitividad del sector del transporte de pasajeros. En este sentido, la Secretaria de Tránsito y Transporte ejerce acciones tendientes fortalecer a las empresas del sector en temas como seguridad vial, legalidad, certificación en competencias laborales, economía solidaria, formalización y generación de empleo, avances de las tecnologías de la comunicación en el sector transporte, responsabilidad frente al cuidado del medio ambiente, entre otros (Gobernación de Boyacá, 2013).

Por otra parte, el tema de la competitividad del transporte de pasajeros en Boyacá ha estado presente en programas departamentales que buscan potenciar a esta región. Los anteriores gobiernos de Boyacá han impulsado proyectos de gran alcance como la consolidación de los anillos turísticos, de acuerdo con las potencialidades de cada región, entre los años 2004 y 2007. También, durante la administración departamental 2012-2015, se consolidó el proyecto Las siete maravillas de Boyacá (Gobernación de Boyacá, 2004, 2008, 2015)(Gobernación de Boyacá, 2004 \#46;Gobernación de Boyacá, 2008 \#47;Gobernación de Boyacá, 2015 \#48). Estos programas articulaban, de cierta forma, acciones tendientes a mejorar las condiciones de competitividad del transporte ya que su ejecución implicó la construcción de carreteras y la capacitación de prestadores del servicio como una actividad conexa al turismo.

De igual forma, el Gobierno departamental ha tratado de aprovechar la ventaja comparativa dada por la estratégica ubicación Boyacá (tan solo a 160 kilómetros al norte de Bogotá). Para ello se ha identificado la región económica de planificación, donde 
se concentran las principales ciudades del departamento (Tunja, Duitama y Sogamoso) que sobresalen por un desarrollo industrial, agropecuario, siderúrgico y comercial. Uno de los logros significativos de los últimos años ha sido la construcción de la doble calzada Briceño - Sogamoso, que conecta a la capital colombiana con la zona económica o corredor industrial, como comúnmente se le llama dado que constituye la principal arteria para el desarrollo del sector de transporte de carga y pasajeros de la región (Gobernación de Boyacá, 2008).

Sin embargo, aún existen en Boyacá zonas de difícil acceso como consecuencia del notorio deterioro de la red vial que no permite ofrecer un servicio de transporte eficiente, de calidad y oportuno. Tal es el caso de zonas como la Provincia de Occidente, donde el deficiente estado de las vías impide llegar al único puerto del departamento sobre el río Magdalena: Puerto Boyacá. En este sentido, es necesario que la administración departamental, a través de proyectos de mejoramiento de infraestructura vial, dinamice el desarrollo sostenible del transporte y, por ende, el de las comunidades.

\section{Conclusiones}

Existe una preocupación inminente de los actores sociales por hacer del transporte una actividad sostenible medioambientalmente, generadora de valor y con un alto compromiso social en el desarrollo de las regiones. En este sentido, a partir de la primera década del siglo $\mathrm{xx}$, empiezan a aparecer estudios relacionados con los sistemas sostenibles de transporte. Esta preocupación se evidencia también en la incorporación de tecnologías en la prestación del servicio, pero especialmente en lo concerniente al mejoramiento de la infraestructura vial y a la construcción de modernas terminales, como en el caso de Tunja y Duitama, y la renovación del parque automotor.

Una de las situaciones que limitan la capacidad de innovación y crecimiento, al menos en el sector del transporte intermunicipal de pasajeros en Colombia, es la débil regulación que estimula, de cierta manera, la informalidad. Esto conlleva a no valorar criterios como la comodidad, agilidad y seguridad, elementos sensibles para la percepción de la calidad del servicio por parte de los usuarios.

La mayor parte de esta revisión documental muestra una preocupación de carácter técnico evidenciada en estudios operacionales, de diseño de rutas, estudios de tiempos de viaje, entre otros. Este enfoque ha dejado a un lado los demás elementos de la competitividad, como la percepción de calidad, los estudios de satisfacción al cliente e innovación en los servicios, lo cual evidencia un vacío en el sector del transporte intermunicipal de pasajeros. Dicho vacío, o, cuando menos, esa información que no es visible, debe llevarnos a pensar una estrategia de socialización de la información sobre los aspectos mencionados.

A nivel internacional, los documentos que se refieren a la competitividad del transporte hacen énfasis en el transporte sostenible, incluyente y responsable. Bajo estas premisas fundamentales se han diseñado las normas técnicas que propenden por la prestación del servicio en condiciones de calidad, oportunidad y seguridad. La consolidación y apoyo del transporte intermunicipal de pasajeros ha sido un tema transversal con el cual se busca potenciar a Boyacá en diversas actividades económicas como el turismo, la industria y el comercio aprovechando las ventajas comparativas de este departamento ubicado en una posición geográfica estratégica por su cercanía con Bogotá.

Los vacíos que existen en materia de estudios de competitividad del transporte intermunicipal de pasajeros se evidencian en las escasas publicaciones realizadas sobre el tema o, al menos, nos estamos refiriendo a estudios que no logra ser visibles. En consecuencia, con la presente aproximación al estado del arte del transporte de pasajeros, surgen diversos temas de investigación: la contribución de las terminales de transporte a la competitividad del sector, informes o boletines sectoriales de competitividad con periodicidad anual, proyectos de trascendencia tecnológica que involucren procesos de innovación y desarrollo, estudios técnicos del transporte teniendo en cuenta factores de sostenibilidad ambiental, equidad social y valor económico, y estudios de caracterización del sector del transporte en Boyacá.

\section{Referencias}

Aktivia Servicios Financieros. (2003). Estudios sectoriales. El transporte terrestre de pasajeros. Recuperado de http:// aktiva.com.co/blog/Estudios\%20sectoriales/2013/ transporte_pasajeros.pdf

Alcalde, P. (2009). Calidad. Madrid: Gráficas Rogar.

Asociación Nacional de Industriales, ANDI. (2012). Transporte interurbano e intermunicipal de pasajeros. Obtenido de http://www.andi.com.co/cst/Paginas/default.aspx

Berni, M., Bajav, S. y Manduca, P. (2005). Biofuels for Urban Transport: Brazilian Potential and Implications for 
Sustainable Development. En C. A. Brebbia y J. W. S. Longhurts (Eds.), Urban Transport and the Environment in the 21st Century (pp. 51-58). Boston, EE.UU.: wiTeLibrary.

Boyacá Sie7e Días. (Noviembre 17 de 2015). Duitama inaugura moderna terminal de transporte de pasajeros. $E l$ Tiempo. Recuperado de http://www.eltiempo.com/colombia/boyaca-7-dias/terminal-de-transportes-se-inaugura-en-duitama/16433889

Brebbia, C. A., y Longhurst, J. W. S. (Eds.). (2005). Urban Transport XI: Urban Transport and the Environment in the 21st Century. Recuperado de https:// books.google.com.co/books?id=Alechd_pX2UC\&pg $=$ PA286\&lpg $=$ PA286\&dq $=$ Urban + trans port $+\mathrm{XI}+:+$ urban + transport + and + the + en vironment + in + the $+21 s t+c e n t u r y \& s o u r-$ $\mathrm{ce}=\mathrm{bl} \&$ ots $=43 \mathrm{Q} 6 \mathrm{w} 08 \mathrm{Y} 64 \& \mathrm{sig}=\mathrm{x} 2 \mathrm{ABONUx}-$ QPb79565wu48kb0mufg\&hl=es\&sa=X\&ved=0ahUKEwiCjZOb1sjJAhXJmx4KHdoKB5QQ6AEIO$\mathrm{DAF} \mathrm{v}=$ onepage $\& \mathrm{q}=\mathrm{Urban} \% 20$ transport $\% 20 \mathrm{XI} \% 20$ \%3A\%20urban\%20transport\%20and\%20the\%20environment $\% 20$ in $\% 20$ the $\% 2021$ st $\% 20$ century\&f=false

Cabo, J. (2014). Gestión de la calidad en las organizaciones sanitarias. Madrid: Diaz Santos.

Castellanos, O. y Ramírez, D. (2013). Competitividad: apropiación y mecanismos para su fortalecimiento. Bogotá: Universidad Nacional de Colombia.

Centro de Noticias onu. (2011). La población mundial crecerá en mil millones en la próxima década. Recuperado de http://www.un.org/spanish/News/story.asp?newsID=26703\#.VmLuo7jhDrc

CEтмо. (2008). Calidad y corresponsabilidad en el transporte público de viajeros por carretera. Madrid: Ministerio de Fomento.

Colmenares, I. J. (2007). Desarrollo sustentable y sostenible de sistemas de transporte público urbano. Impacto en la gerencia, organización y liderazgo (Ponencia presentada en el Seminario "Administración: Teorías y categorías de análisis", Caracas, Venezuela). Recuperado de http://www.monografias.com/trabajos-pdf2/ desarrollo-sistemas-transporte-publico-urbano/desarrollo-sistemas-transporte-publico-urbano.pdf

Consejo Privado de Competitividad. (2007). ¿A dónde queremos llegar? Visión 2032 y principales estartegias. En C. P. Competitividad, Informe nacional de competitividad (pp. 15-41). Bogotá: Punto y Línea Impresores.

Consejo Privado de Competitividad. (2015). Informe nacional de competitividad 2015-2016. Bogotá: Zetta Comunicaciones.
Consejo Privado de Competitividad y Universidad del Rosario. (2015). Índice departamental de competitividad. Bogotá: Zetta Comunicaciones.

Departamento Nacional de Planeación. (2003). CONPES 3260. Política nacional de transporte urbano y masivo. Bogotá: Consejo Nacional de Política Social y Económica.

Departamento Nacional de Planeación. (2006). Institucionalidad y principios rectores de política para la competitividad y productividad. Bogotá.

Departamento Nacional de Planeación. (2008). CONPES 3527. Política nacional de competitividad y productividad. Bogotá: Consejo Nacional de Política Social y Económica.

Esser, K., Hillebrand, W., Messener, D. y Stamer, J. M. (1994). Competitividad sistémica. Berlín: Instituto Alemán de Desarrollo

Fernández, R., Álvarez, V., Ortega, F. y Martínez, G. (2011). Valoración ambiental del uso de combustibles alternativos en flotas de autobuses. Ponencia presentada en el xv Congreso Internacional de Ingeniería de Proyectos, Huesca.

Gallo, G. (26 de agosto de 2012). El transporte terrestre pide pista en la guerra de tarifas aéreas, El Colombiano.

Gobernación de Boyacá. (2004). Plan de desarrollo "Boyacá deber de todos", 2004-2007.

Gobernación de Boyacá. (2008). Plan departamental de desarrollo "Para seguir creciendo", 2008-2011.

Gobernación de Boyacá. (2013). Seminario de la Gobernación "Empresas de Transporte Productivas y Seguras". Recuperado de http://www.boyaca.gov.co/prensa-publicaciones/noticias/1046-gobernaci\%C3\%B3n-realizar\%C3\%A1-seminario-taller-\%E2\%80\%9Cempresas-de-transporte-de-boyac\%C3\%A1-productivas-y-seguras $\% \mathrm{E} 2 \% 80 \% 9 \mathrm{D}$

Gobernación de Boyacá. (23 de octubre de 2013). Construir Terminal de Transportes de Tunja fue una decisión concertada: Juan Carlos Granados. Recuperado de http://www.boyaca.gov.co/ prensa-publicaciones/fotonoticias/1244-v\%C3\%ADa-libre-al-terminal-de-transporte-dio-el-gobernador-de-boyac\%C3\%A1-en-la-asamblea-2

Gobernación de Boyacá. (2015). Plan departamental de desarrollo "Boyacá se atreve", 2012-2015.

Gobierno de Colombia. (2014). Plan Nacional de Desarrollo “Todos por un nuevo país”, 2014-2018.

González, S. (2004). Calidad e imagen el transporte de viajeros en autobús: Norma UNE 13816. Medición de la calidad en el transporte de pasajeros. Asociación 
Española de Normalización y Certificación -AENOR. Recuperado de http://www.fundacioncetmo.org/fundacion/seminarios2004/QI/SGonzalez.pdf

Hernández, M. (2006). La competitividad sistémica: elemento fundamental de desarrollo regional y local. Ciencia y Mar, 29, 39-46.

Lombana, J. y Rozas-Gutiérrez, S. (2008). Marco analítico de la competitividad. Fundamentos para el estudio de la competitividad regional. Pensamiento y gestión, 26, 1-38.

Lombarca, N. (2007). Consideraciones teóricas de la competitividad. Omnia, 13(2), 158-184.

Maeso, E., González G. y Pérez, P. (2012). Combustibles y sistemas de propulsión en el transporte público urbano en autobús (Ponencia presentada en la 6th International Conference on Industrial Engineering and Industrial Management).

Malasek, J., y Jazdzik_Osmólska, A. (2005). Decalogue for Sustainable Urban Transport Strategy. In C. A. Brebbia y J. W. S. Longhurts (Eds.), Urban Transport and the Environment in the 21st Century. Boston, EE.UU.: witeLibrary.

Mejía, C. (Mayo 30 de 2008). Un factor de competitividad y diferenciación. Portafolio. Recuperado de http://www. portafolio.co/economia/finanzas/factor-competitividad-diferenciacion-369602

Meyer, W. (2003). Billete para el futuro. 3 paradas de la movilidad sostenible. Recuperado de http://www.railway-mobility.org/docs/uitpticket_es.pdf

Ministerio de Transporte. (2001) Resolución 3600 de 2001: "Por medio de la cual se establecen tarifas mínimas para la prestación del Servicio Público de Transporte Terrestre Automotor de Pasajeros por Carretera”.

Mintransporte. (2015). Minsiterio de Transporte. Recuperado de https://www.mintransporte.gov.co/publicaciones.php?id=33

Monzón, A., y López, M. (2009). Planes de movilidad urbana. ¿Agentes de cambio o cambio de agentes? Recuperado de http://www.ciccp.es/revistait/textos/pdf/03.\%20 Andr\%C3\%A9s\%20Monz\%C3\%B3n.pdf

Morales, M. E., y Castellanos, O. (2007). Estrategias para el fortalecimiento de las PYME de base tecnológica a partir del enfoque de competitividad sistémica. Innovar, 17(29), 115-136

Páramo, F. (2013). La investigación en ciencias sociales: Estrategias de investigación. Bogotá: Universidad Piloto de Colombia.

Piñeiro, M., Jaffe, W., Müller, G., Gamboa, C., Madeley, J., Valle, L. D. y Olechowski, A. (1993). Innovation, Competitiveness and Agro-industrial Development. París: IICA.
Porter, M. (1985). Ventaja competitiva. México: CECSA.

Porter, M. (1997). De la ventaja competitiva a la estrategia corporativa. Artes y oficios de la gerencia. Bogotá: Norma.

Porter, M. (2008). Las cinco fuerzas competitivas que le dan forma a la estrategia. Harvard Business Review América Latina, 18. Recuperado de http://insight.ipae. edu.pe/media/contents/articulos/file/041764500\%20 1334671639.pdf

Presidencia de la República de Colombia. (1996). Decreto 0491 de 1996: por el cual se reglamenta el Capítulo XIII del Título II del Decreto 2150 de 1995.

Presidencia de la República de Colombia. (2001). Decreto 171 de 2001: "Por el cual se reglamenta el Servicio Público de Transporte Terrestre Automotor de Pasajeros por Carretera. Ministerio de Transporte".

Presidencia de la República de Colombia. (2002). Decreto 1485 de 2002: "Por el cual se reglamenta el fondo nacional para la reposición y renovación del parque automotor del servicio público de transporte terrestre de pasajeros".

Presidencia de la República de Colombia. (2006). Decreto 4668 de 2006: "Por el cual se establecen unas disposiciones relacionadas con el capital pagado o patrimonio líquido de las empresas asociativas del sector solidario o cooperativas de transporte terrestre automotor".

Pucher, J., Korattyswaroopam, N., y Ittyerah, N. (2004). Urban Transport in India: Issues, Challenges, and the Way Forward. Public Transport International, 53(2).

RAE. (2001). Diccionario de la lengua española (22ava Edición.). España: Real Academia Española.

Rodriguez, D. y Becerra, C. (2014). Competitividad del sector transporte intermunicipal de pasajeros en Boyacá. Inquietud Empresarial, XIV(2), 33-67.

Romo, D. y Musik, G. (2005). Sobre el concepto de competitividad. Comercio Exterior, 55(3), 200-214.

Schwab, K. (Ed.). (2015). Ginebra: World Economic Forum.

Tobón, A. (2009). Análisis sobre la evolución reciente del sector transporte en Colombia. Perfil de Coyuntura Económica, 13, 147-163.

Velasco, A. y Heredia, A. (2004). Regiones, competitividad y desarrollo en México. Problemas del desarrollo. Revista Latinoamericana de Economía, 35(138), 11-31.

World Economic Forum's Global Competitiveness Report, 2014-2015. Recuperado de http://reports.weforum. org/global-competitiveness-report-2014-2015/. Switzerland: World Economic Forum. 